\title{
APLICAÇÃO DE UMA HISTÓRIA EM QUADRINHOS, TRINITY, NA EDUCAÇÃO EM QUÍMICA
}

\author{
Guilherme Balestiero da Silva ${ }^{\mathrm{a}}$, Carolina Sotério ${ }^{\mathrm{a}}$ S Salete Linhares Queiroz ${ }^{\mathrm{a}, *,(\mathbb{C}}$ \\ anstituto de Química de São Carlos, Universidade de São Paulo, 13560-970 São Carlos - SP, Brasil
}

Recebido em 01/12/2020; aceito em 18/02/2021; publicado na web em 12/03/2021

\begin{abstract}
THE APPLICATION OF A COMIC STRIP, TRINITY, IN CHEMISTRY EDUCATION. Faced with obstacles encountered in lessons and the search for actions that meet current educational needs, some attention has been paid to the role of comics as instructional tool. This article focuses on the use of a comic strip, Trinity: A Graphic History of the First Atomic Bomb, to develop knowledge and promote science learning. Three case studies were extracted from the comic and implemented to a group of pre-service chemistry teachers. A questionnaire was utilized to assess their perceptions about the usefulness of comics for their learning. One hundred percent of students indicated that comics helped improve their understanding of the nature of science. On the basis of the data, comic strips may be utilized as an acceptable educational tool in science education.
\end{abstract}

Keywords: teaching strategy; comic strip; pre-service teachers; argumentation.

\section{INTRODUÇÃO}

Não é de hoje que os educadores têm buscado metodologias inovadoras que permitam amenizar as dificuldades que se apresentam em espaços formativos. No que tange ao ensino de ciências, esses obstáculos podem adquirir uma dimensão ainda maior quando o estudante entra em contato com inúmeros conceitos abstratos. ${ }^{1}$

A exigência por metodologias inovadoras no ensino de ciências é também sustentada quando se assume como papel fundamental da educação científica o seu objetivo social. Esse propósito, por sua vez, implica em fazer com que os educandos, para além de tópicos conceituais, tomem conhecimento da prática científica, compreendendo, ao menos parcialmente, o seu funcionamento. ${ }^{2}$

Nesse contexto, em especial a partir do final do século XX e início do século XXI, o emprego de histórias em quadrinhos (HQ) tem atraído gradativamente a atenção de educadores. ${ }^{3}$ De fato, trabalhos publicados em anais do Encontro Nacional de Ensino de Química (ENEQ) e do Encontro Nacional de Pesquisa em Educação em Ciências (ENPEC) evidenciam o crescente número de relatos sobre esse gênero textual. ${ }^{4,5}$ Cabe destacar que neste artigo é adotado o termo hipergênero textual quando é feita referência à HQ, uma vez que estas abarcam outros tantos gêneros, como tirinhas cômicas, mangás etc. ${ }^{6}$

Tomando a discussão a respeito desse hipergênero textual como foco de atenção, o qual é definido por Eisner $^{7}$ como uma forma de arte sequencial estruturada pela imagem e pela escrita, HQ correspondem a um tipo de leitura, em princípio fácil, e bastante próxima daquela espontânea dos educandos, principalmente dos níveis fundamental e médio. Gozando de características próprias e uma linguagem autônoma, o seu emprego no contexto da educação científica tornase promissor devido a fatores, os quais Testoni ${ }^{8}$ sumariza como sendo: ludicidade, linguagem e o cognitivismo inerente à sua leitura. Comumente de caráter cômico, as obras quadrinizadas costumam exibir um equilíbrio entre arte e ludicidade, proporcionando uma leitura livre e despreocupada.

O potencial pedagógico desse hipergênero textual sugere uma diversidade de aplicações que tem sido gradualmente estudada no campo do ensino de ciências. Sobre essas possibilidades, Leite, ${ }^{9}$ interessado principalmente no seu aspecto lúdico associado à utilização de tecnologias da informação e comunicação, salienta que

\footnotetext{
*e-mail: salete@iqsc.usp.br
}

HQ, no contexto da educação científica, são interessantes não somente para a discussão de conteúdos científicos, como também permitem dramatização e divulgação da ciência. Outro aspecto reforçado pelo autor é o incentivo à leitura, com destaque para aqueles estudantes que não são motivados a ler outro gênero além de HQ.

Tendo em vista os aspectos apresentados, este trabalho tem como objetivo relatar uma experiência de ensino pautada na utilização de uma obra quadrinizada em contexto de formação inicial de professores de química, investigando suas percepções a respeito das contribuições trazidas por ela. Pretende-se, dessa forma, colaborar com a ampliação de iniciativas dessa natureza no ensino de química. A análise que subsidiou a escolha da HQ empregada em sala de aula é apresentada no tópico a seguir.

\section{TRINITY: A HISTÓRIA EM QUADRINHOS DA PRIMEIRA BOMBA ATÔMICA}

Publicada em 2013 no Brasil pela editora Três Estrelas, a obra quadrinizada empregada em sala de aula é denominada Trinity: a história em quadrinhos da primeira bomba atômica, de autoria do norte-americano Jonathan Fetter-Vorm. ${ }^{10} \mathrm{O}$ estudo das suas características, antes da decisão sobre a discussão a respeito da HQ com os licenciandos, foi realizado a partir do Quadro Analítico proposto por Ferreira e Queiroz, ${ }^{11}$ com base no trabalho de Salem e Kawamura, ${ }^{12}$ o qual permite analisar textos de divulgação científica (TDC) no que tange a seu conteúdo e sua forma (Quadro 1). Destacados em cinza estão os elementos mais comuns da subcategoria forma para as HQ.

Em estudo recente publicado nesta revista, o Quadro 1 foi empregado por Sotério e Queiroz ${ }^{13}$ no contexto de um curso de comunicação pública da ciência oferecido a bacharelandos em química.

\section{Análise do Conteúdo da HQ}

Com base no Quadro 1, ao investigarmos o conteúdo da HQ, podemos, em uma análise geral, identificar a que dimensão do conhecimento a informação científica veiculada no texto se relaciona: química, fronteiras ou temas transversais. A primeira subcategoria, química, diz respeito a conteúdos tipicamente abordados no ensino formal desse componente curricular, como a constituição da matéria ou transformações químicas. A segunda subcategoria, fronteiras, 
Quadro 1. Quadro Analítico de Ferreira e Queiroz ${ }^{11}$

\begin{tabular}{|c|c|c|c|c|c|}
\hline \multicolumn{6}{|c|}{ ANÁLISE HQ } \\
\hline \multicolumn{6}{|c|}{ CONTEÚDO } \\
\hline \multicolumn{3}{|c|}{ ANÁLISE GERAL } & \multicolumn{3}{|c|}{ ANÁLISE ESPECÍFICA } \\
\hline Química & Fronteiras & Temas Transversais & Temática & $\begin{array}{l}\text { Características da } \\
\text { atividade científica }\end{array}$ & Abordagem \\
\hline \multicolumn{6}{|c|}{ FORMA } \\
\hline Linguagem & Estrutura & \multicolumn{4}{|c|}{ Recursos visuais e textuais } \\
\hline Linguagem verbal & Transições de cena & Letreiramento & Imagem/Desenho & Planos de visão & Ângulos de visão \\
\hline
\end{tabular}

compreende tópicos presentes em áreas ou componentes curriculares correlatos à química, como a física. São exemplos de tópicos dessa natureza conceitos de eletricidade. A terceira e última subcategoria abarca os temas transversais, que não são intrínsecos a nenhum componente curricular, mas permeiam todos eles nos mais variados níveis de ensino. ${ }^{14}$

No que diz respeito à HQ, embora existam, como esperado, tópicos que se relacionam fortemente com a química, em especial quanto a sua linguagem simbólica, e aqueles que podem ser classificados na fronteira entre física e química, como a noção de radioatividade e processos como fissão nuclear, são proeminentes as temáticas transversais. Com efeito, especialmente questões éticas, intrínsecas ao desenvolvimento científico e tecnológico, ganham destaque. Por exemplo, ao tecer considerações a respeito das consequências dos esforços empreendidos pelos cientistas no Projeto Manhattan, responsável pela idealização de uma bomba atômica, o autor apresenta o questionamento:

[Narrador] Os cientistas voltaram do Japão com relatórios detalhados sobre as cidades destruídas e seus habitantes devastados. Pela primeira vez, Oppenheimer e todos em Los Alamos tinham uma visão completa daquilo que haviam criado. Finalmente eles tinham a resposta para a pergunta que vinham se fazendo havia anos: [Cientista] Pode ser feito? [Narrador] Depois do Projeto Manhattan, todavia, muitos cientistas se sentiram na obrigação de fazer uma pergunta diferente: [Cientistas] Deveria ter sido feito? (p. 136). ${ }^{10}$

Ainda com relação ao conteúdo, a análise específica de um TDC consiste em identificar sua temática, a presença ou não de características da atividade científica e a abordagem utilizada pelo autor para veicular a informação. Assim sendo, a HQ tem como temática a construção de bombas atômicas e suas implicações. A presença de características da atividade científica, por sua vez, é nela recorrente. Com efeito, ao discutir a respeito das implicações da construção de um armamento nuclear, o autor faz menção a tais características, como: metodologias e formas de interpretação de resultados; atributos pessoais dos pesquisadores/cientistas; eventos marcantes, como a conquista de prêmio Nobel; financiamento de pesquisas etc. Logo, ao apresentar características que aproximam o leitor da prática científica, a HQ pode contribuir na atenuação de visões distorcidas da ciência.

Por fim, no que diz respeito à subcategoria abordagem, que se refere às formas de contextualização da temática empregadas pelo autor, na HQ ocorrem, simultaneamente, a histórica, a conceitual e a polêmica.

\section{Análise da Forma da HQ}

Ferreira e Queiroz ${ }^{11}$ propõem três subcategorias de análise para a forma de um TDC: a linguagem, a estrutura, e os recursos visuais e textuais. O estudo da linguagem consiste em observar os recursos linguísticos empregados pelo autor para tornar o conteúdo mais acessível ao seu interlocutor. São alguns desses recursos a presença de metáforas, analogias, simplificações, enunciados explicativos etc. Investigar a estrutura implica em verificar como as informações estão encadeadas no texto (destacadas em boxes, colocadas em tópicos dependentes ou independentes entre si, por exemplo), enquanto tomar conhecimento dos recursos visuais e textuais consiste em observar a distribuição espacial das informações, por exemplo, por meio de representações esquemáticas, fotografias e infográficos.

Com relação à primeira subcategoria, a linguagem das HQ, conforme explicitado na literatura, é estruturada pela imagem e pela escrita. ${ }^{7}$ Por sua vez, na perspectiva de Ramos, ${ }^{6}$ ler quadrinhos equivale a ler sua linguagem, tanto em seu aspecto verbal quanto visual (não verbal). Contudo, considerando as perspectivas presentes no Quadro 1, neste artigo os aspectos visuais ou não verbais da HQ serão relacionados à subcategoria recursos visuais e textuais.

Quanto à linguagem verbal empregada no texto quadrinizado em questão, observa-se a busca por um equilíbrio entre termos técnicos/ científicos e expressões informais comuns ao cotidiano do leitor. A busca por esse equilíbrio é natural, uma vez que, direcionado a um público-alvo diverso, não necessariamente iniciado na cultura científica, a obra precisa contar com uma linguagem de fácil compreensão. Para tanto, diversos recursos linguísticos, como os destacados a seguir, estão nela presentes: analogias; metáforas; estratégias de definição (definição por conceituação e por nomeação); enunciados comparativos etc. Em contexto formativo esse equilíbrio é bem-vindo, pois permite não somente a compreensão de diferentes conceitos, como também a aproximação do leitor com termos técnicos e científicos.

Analogia: [Narrador]. Nesse modelo, vamos dizer que fissão é o ato de empurrar uma peça de dominó. Se as peças estiverem muito afastadas, a 'reação' para, mas se estiverem perfeitamente alinhadas - perto o bastante umas das outras - então tudo o que você tem de fazer é derrubar o primeiro dominó da fila (p. 40). ${ }^{10}$

Metáfora: [Narrador] Escondido no coração de cada átomo há um minúsculo e incrivelmente denso aglomerado de partículas carregadas (p. 5 ,). ${ }^{10}$

Definição por nomeação: [Narrador] Se você deixar uma barra de urânio parada por 4,5 bilhões de anos, é possível que metade dela se transforme em chumbo. Isso é chamado de decaimento radioativo... (p. 4). ${ }^{10}$

A respeito da subcategoria estrutura, no que diz respeito às $\mathrm{HQ}$, destacam-se as transições de cena. Ao permitir a passagem de um quadro para outro, essas transições estabelecem a noção de tempo e espaço e imprimem o caráter sequencial à narrativa. Logo, é por meio dela que se pode inferir como é feita a continuidade da narrativa e como as informações estão encadeadas. Existem várias possibilidades de transições as quais, mediante a quantidade de 
informações subentendidas na passagem entre um quadro e outro, demandam uma atenção maior ou menor do leitor. ${ }^{6}$ Nas transições, como a momento-para-momento, as ações e reações dos personagens estão representadas passo a passo, enquanto que as transições do tipo cena-para-cena são marcadas por saltos temporais e/ou espaciais significativos. $^{6}$

Na HQ em questão, as transições observadas estão em consonância com a natureza dos quadrinhos ocidentais, e se tornam particularmente relevantes para enfatizar os saltos temporais exigidos pela abordagem histórica adotada. Logo, ao empregar principalmente transições cena-para-cena, a correta compreensão da narrativa exige um leitor atento, que dever ser capaz de identificar os diferentes espaços e momentos representados em cada cena.

A subcategoria recursos visuais e textuais contemplou elementos da HQ como o letreiramento, as imagens ou desenhos, e os planos e ângulos de visão. Quanto ao letreiramento, este relaciona-se à escolha de fontes e efeitos visuais que permitem um novo significado a uma palavra, como a percepção de som que ela expressa. São alguns recursos dessa natureza comuns na HQ: a presença de falas em letras maiúsculas para alguns personagens e minúsculas para outros; onomatopeias; negritos; itálicos etc. Em geral, o letreiramento observado no texto contribui para promover uma maior sensibilização no leitor, bem como o auxilia no entendimento da narrativa. Para tanto, informações importantes para a sua compreensão, ou para evidenciar a polêmica em discussão, como o poder de destruição de armamentos nucleares, são destacadas em letras maiúculas, conforme ilustra o texto a seguir.

[Narrador] Um dos primeiros desafios de Groves foi tentar separar os cientistas; muitos deles se recusaram totalmente a fazer isso. [Sargento] ELES IGNORAM SUAS ORDENS SENHOR! O QUE DEVO FAZER? [Groves] SÃO UM BANDO DE CRIANÇAS. ELES SÓ PRECISAM DE UM POUCO DE DISCIPLINA (p. 35). ${ }^{10}$

O emprego de fontes especiais, como o uso de negrito é presente para destacar, por exemplo, o sigilo e a necessidade de segurança do Projeto Manhattan. É o caso do trecho em que o leitor se depara com uma das placas com a seguinte inscrição: “ÁREA RESTRITA SÓ PESSOAL AUTORIZADO” (p. 34).${ }^{10} \mathrm{~A}$ onomatopeia, por sua vez, é empregada pelo autor a partir do termo CLIC (p.42), ${ }^{10}$ que permite a expressão de som em uma reação de fissão nuclear controlada.

No que diz respeito aos desenhos e imagens, para $\mathrm{McCloud}^{15}$ é a escolha pelos traços e a caracterização dos personagens, ora mais cartunescos, ora mais realistas, responsáveis por parte significativa do sucesso desse hipergênero textual, pois é por meio de tal elemento que ocorre a identificação leitor/personagem. Em especial, no ensino de ciências, esse elemento é interessante ao permitir uma maior aproximação e identificação entre leitor e cientista, desmistificando a imagem deste último.

Quanto ao desenho e aos traços, destaca-se também a presença dos jargões visuais na perspectiva de Kress. ${ }^{16}$ Para o autor, de forma semelhante aos jargões verbais, há na ciência esquemas e símbolos devidamente consolidados e próprios da comunidade científica. Uma análise das imagens e desenhos presentes na HQ permite reforçar a importância que esses jargões assumem para a compreensão de conceitos pertinentes ao ensino de química e física. É por meio de desenhos e esquemas que se torna possível, por exemplo, a visualização de modelos da ciência. Sendo assim, o emprego de imagens, bem como a utilização de analogias no que tange ao uso de recursos verbais, confere ao texto um elevado grau de didaticidade, ${ }^{17}$ isso é, de aproximação com elementos próximos ao discurso didático e de sala de aula, como enunciados explicativos e visualizações.

A análise dos planos de visão e ângulos de visão permite conhecer como a imagem é apresentada para o leitor e como este a enxerga, respectivamente. É nesse momento que se identifica se o foco da ilustração é na figura humana, na sua expressão ou no ambiente, além de ser possível verificar se o leitor vê a imagem na altura dos olhos, de cima para baixo ou vice-versa. Em suma, a variedade de planos de visão observada na $\mathrm{HQ}$, ora com foco na expressão dos personagens, ora no cenário como um todo, contribui para aumentar o caráter polêmico da narrativa e sensibilizar o interlocutor.

Isso exposto, o Quadro 2 sintetiza a análise da HQ e evidencia que, por apresentar tópicos relacionados à química, às suas fronteiras e temáticas transversais, são promissoras as abordagens a adotar a partir da sua leitura em aulas de química. A presença majoritária do tema transversal (notadamente a ética), por meio de uma abordagem polêmica, é digna de nota, pois possibilita a elaboração de estratégias didáticas voltadas à promoção da argumentação, do pensamento crítico, da compreensão da ciência como empreendimento humano e da avaliação das suas aplicações e implicações políticas e socioambientais.

A análise da HQ (Quadro 2) também aponta para a necessidade de salientar que alguns dos recursos empregados pelo autor para aumentar a didaticidade ${ }^{17}$ do texto (por exemplo, uso de analogias, metáforas, desenhos etc.) exigem uma mediação cuidadosa do docente, uma que vez podem implicar na distorção de informações e desenvolvimento de concepções equivocadas sobre as temáticas em estudo. ${ }^{18}$

Quadro 2. Análise do conteúdo e da forma da HQ Trinity

\begin{tabular}{|c|c|c|c|c|c|}
\hline \multicolumn{6}{|c|}{ HQ TRINITY } \\
\hline \multicolumn{6}{|c|}{ CONTEÚDO } \\
\hline ANÁLISE GERAL & \multicolumn{5}{|c|}{ ANÁLISE ESPECÍFICA } \\
\hline $\begin{array}{l}\text { Tema Transversal: } \\
\text { ética }\end{array}$ & \multicolumn{2}{|c|}{$\begin{array}{l}\text { Temática: construção de bombas atômicas e suas } \\
\text { implicações }\end{array}$} & \multicolumn{2}{|c|}{$\begin{array}{l}\text { Características da atividade científica: metodo- } \\
\text { logias e formas de interpretação de resultados; } \\
\text { atributos pessoais dos pesquisadores/cientistas; } \\
\text { eventos marcantes, como a conquista de prêmio } \\
\text { Nobel; financiamento de pesquisas etc. }\end{array}$} & $\begin{array}{l}\text { Abordagem: histórica, } \\
\text { conceitual e polêmica }\end{array}$ \\
\hline \multicolumn{6}{|c|}{ FORMA } \\
\hline \multicolumn{2}{|c|}{$\begin{array}{l}\text { Linguagem verbal: equilíbrio entre termos técni- } \\
\text { cos/científicos e expressões comuns ao cotidiano } \\
\text { do leitor, uso de metáforas e analogias }\end{array}$} & \multicolumn{2}{|c|}{$\begin{array}{c}\text { Desenhos e imagens: caracterização dos perso- } \\
\text { nagens, que permite uma maior aproximação e } \\
\text { identificação do leitor, e o emprego de jargões } \\
\text { visuais, como modelos da ciência }\end{array}$} & \multicolumn{2}{|c|}{$\begin{array}{l}\text { Letreiramento: falas em letras maiúsculas para } \\
\text { alguns personagens e minúsculas para outros; } \\
\text { onomatopeias; negritos e itálicos }\end{array}$} \\
\hline \multicolumn{2}{|c|}{$\begin{array}{l}\text { Transições de cena: destaque para transições do } \\
\text { tipo cena-para-cena e saltos temporais }\end{array}$} & \multicolumn{2}{|c|}{$\begin{array}{l}\text { Planos de visão: planos de visão que reforçam } \\
\text { desde a expressão dos personagens principais ao } \\
\text { cenário devastado pela bomba atômica }\end{array}$} & \multicolumn{2}{|c|}{$\begin{array}{c}\text { Ângulos de visão: majoritariamente na altura dos } \\
\text { olhos do leitor }\end{array}$} \\
\hline
\end{tabular}




\section{LEITURA E DISCUSSÃO DA HQ: CONTEXTO DE APLICAÇÃO DA PROPOSTA}

Analisada e selecionada a HQ, a sua leitura ocorreu no componente curricular Química, Sociedade e Cotidiano, do Curso em Licenciatura em Ciências Exatas da Universidade de São Paulo. Essa é obrigatória para os alunos que fizeram a opção pela Habilitação em Química, sendo sugerida para o oitavo semestre. No período de aplicação da proposta, segundo semestre de 2017, as aulas foram ministradas às terças-feiras, das $19 \mathrm{~h}$ às $21 \mathrm{~h}$.

O objetivo principal do componente curricular é o desenvolvimento da capacidade de investigação e análise crítica dos educandos por meio do conhecimento, discussão e posicionamento diante de problemas relacionados ao impacto da química na sociedade. Assim, a análise prévia da HQ, apresentada no tópico anterior, indicou a pertinência para a inserção da sua leitura no contexto educativo.

Quanto aos sujeitos participantes das atividades, foram sete licenciandos, os quais representavam um grupo bastante heterogêneo. No total, cinco eram do sexo feminino e dois do sexo masculino. Três dos sete alunos já haviam concluído outra graduação, sendo dois bacharéis em química e uma engenheira química. Desses três, uma licencianda já possuía título de doutora em química e outra cursava a pós-graduação concomitantemente ao curso de Licenciatura. Para os quatro alunos restantes, apesar de não possuírem nenhum diploma de graduação, dois já haviam se matriculado em outro curso de nível superior, antes do ingresso na Licenciatura.

A heterogeneidade do grupo também se estende à relação dos estudantes com as HQ, a qual perpassava um cenário de extrema à pouca familiaridade. Com idades variadas, apenas uma das licenciandas afirmava possuir um contato mais frequente com esse tipo de texto, em especial com o gênero oriental mangá. Obras quadrinizadas também fizeram parte do repertório de leitura de outros dois licenciandos, ambos em sua segunda graduação. Seja no formato de obras de super-heróis ou quadrinhos nacionais, como a Turma da Mônica de Maurício de Sousa, a leitura de HQ foi bastante comum na infância dos mesmos, que foram gradativamente se afastando desse tipo de texto. Os outros quatro licenciandos afirmaram ter consumido HQ esporadicamente, com destaque para o gênero de tirinhas cômicas, populares em jornais e, mais recentemente, em páginas de compartilhamento online. A caracterização dos licenciandos ocorreu por meio de uma discussão conduzida pelo docente, tendo sido a captação das discussões e interações estabelecidas em todas as aulas realizada com base no uso de gravadores de áudio.

Cabe destacar que na ocasião da aplicação das atividades, eram constantemente divulgadas notícias a respeito de um possível conflito bélico envolvendo Estados Unidos da América e Coréia do Norte. A iminência de um fato como este colocou em evidência discussões éticas, morais e científicas sobre a construção de bombas atômicas, o que, provavelmente, ampliou o interesse pela obra de Fetter-Vorm. ${ }^{10}$

As percepções dos estudantes sobre a atividade desenvolvida e o gênero textual trabalhado foram investigadas a partir da aplicação de um questionário em escala Likert de cinco pontos $(\mathrm{CF}=$ Concordo Fortemente; $\mathrm{C}=$ Concordo; $\mathrm{I}=$ Indeciso; $\mathrm{D}=$ Discordo $; \mathrm{DF}=$ Discordo Fortemente), contendo dez afirmações sobre o assunto, cujas respostas serão discutidas em tópico a seguir.

\section{LEITURA E DISCUSSÃO DA HQ: ETAPAS DE APLICAÇÃO DA PROPOSTA}

Atividades integrantes da proposta de ensino ocorreram ao longo de oito encontros com duração de aproximadamente 100 minutos cada. Neste ínterim, ocorreu a leitura completa da HQ, a qual conta com 151 páginas. Para tanto, a obra foi fragmentada de modo que, em cada aula, os alunos fossem progredindo na leitura e cumprindo demandas vinculadas ao texto.

Um panorama sobre a aplicação da proposta é apresentado inicialmente e, na sequência, as ações realizadas em cada um dos encontros são descritas.

\section{Panorama geral}

As atividades foram divididas em quatro categorias: leitura da HQ; atividades escritas sobre a obra quadrinizada; aplicação de estudos de caso extraídos da HQ; e feedback do docente e dos colegas (Processo de Peer-Review (PPR) ou de revisão por pares) frente ao processo ocorrido (Figura 1).

Cabe ressaltar que antes do início da leitura, os alunos estudaram o Modelo de Tomada de Decisão Kortland ${ }^{19}$ e o Modelo de Argumento de Toulmin, ${ }^{20}$ ferramentas que se mostraram essenciais para o bom andamento dos encontros.

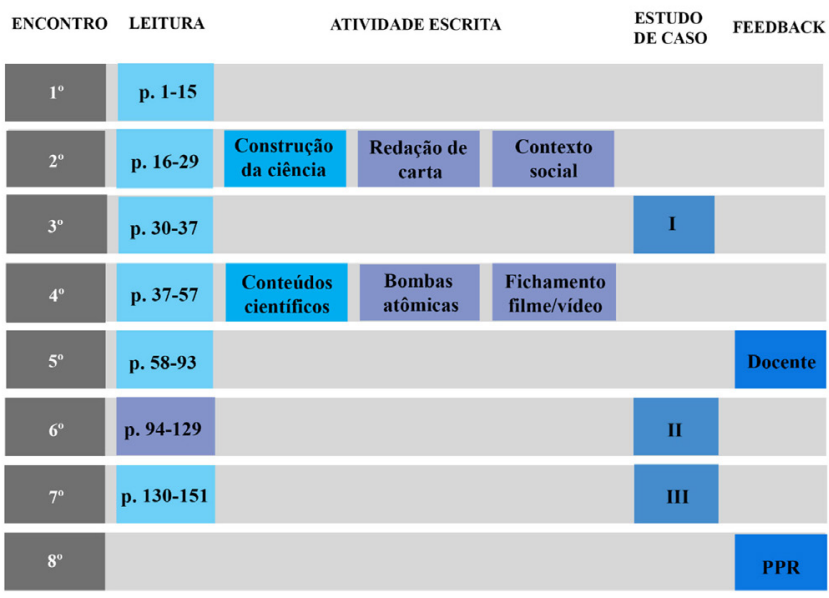

Figura 1. Síntese das atividades realizadas no componente curricular Química, Sociedade e Cotidiano. Atividades extraclasse estão destacadas na cor roxa

Conforme ilustra a Figura 1, o componente curricular contou com atividades de leitura da HQ em sala de aula, desde o primeiro até o quinto encontro, retomadas no sétimo encontro. No sexto encontro, ocorreu a recomendação de leitura em período extraclasse (destaque na cor roxa). A esquematização da dinâmica de leitura em sala (Figura 2) mostra que, ao receberem o fragmento do texto da HQ (I), os educandos (representados por Estudante A e Estudante B) tinham papéis (II) atribuídos pelo professor (relacionados a personagens que integram a obra, como o sargento Daniels, Oppenheimer e o narrador) e realizavam leitura conjunta em voz alta (III). No terceiro, sexto e sétimo encontros, a leitura foi sucedida por atividades relacionadas a um estudo de caso (IV), enquanto que no quinto e no sétimo a leitura foi seguida de oferecimento de feedback pelo docente e pelos colegas sobre atividades a ela vinculada, respectivamente.

Nos dois encontros restantes, segundo e quarto, atividades escritas foram solicitadas, tendo sido elaboradas com base nos fragmentos de texto que haviam sido lidos nas ocasiões. Estas foram realizadas em sala e em período extraclasse (destaque na cor roxa na Figura 1), incluindo a solicitação de redação de cartas hipoteticamente endereçadas a líderes políticos, levantamento do contexto social da época, pesquisa sobre bombas nucleares e fichamento de filmes e vídeos sobre o assunto.

A esquematização da dinâmica das atividades relacionadas a estudos de caso (Figura 3) mostra que os alunos, após a leitura do caso (I), sempre finalizado com questionamento sobre determinada problemática, tomavam posições e elaboravam argumentos escritos 

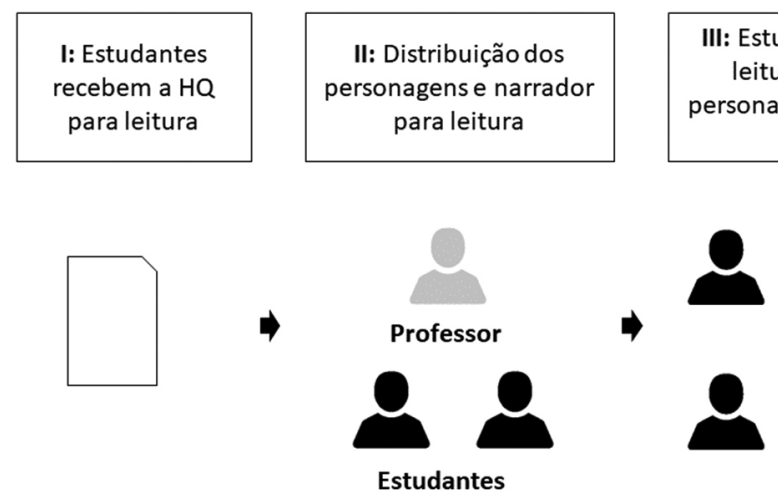

Estudante A

Assume o papel de um personagem

Estudante B

Assume o papel de outro personagem

Figura 2. Esquematização da dinâmica de leitura da $H Q$
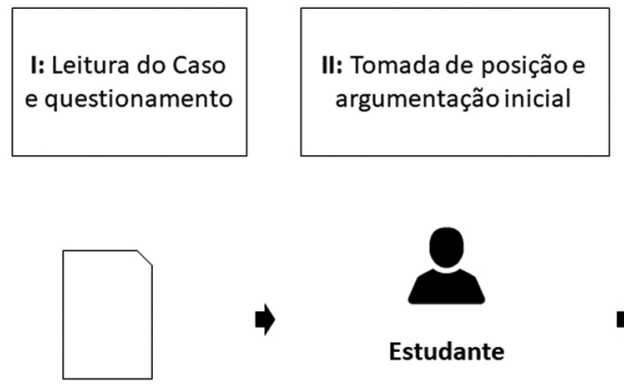

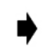

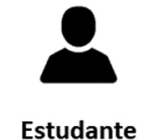

Figura 3. Esquematização da dinâmica de aplicação dos estudos de caso

de forma individual frente a ela (II). Na sequência, o docente mediava uma discussão sobre os posicionamentos adotados (III), encaminhada no sentido de contemplar a identificação dos pontos de conflito que permeavam o caso e das partes interessadas na situação descrita na narrativa. Após a discussão, os estudantes redigiam novos argumentos sobre a problemática, que podiam ser coincidentes ou diferentes dos apresentados inicialmente (IV). Para efeito de maior clareza e entendimento sobre o formato dos casos, o Material Suplementar do presente artigo traz, na íntegra, o primeiro deles, denominado $A$ questão do sigilo no Projeto Manhattan (Caso I), elaborado a partir de excertos extraídos da HQ (páginas 33 a 36).

Expostas as dinâmicas recorrentemente adotadas ao longo do componente curricular em relação ao uso da HQ, tem-se o detalhamento de cada um dos encontros.

\section{Detalhamento dos Encontros}

Primeiro Encontro: foi apresentada aos licenciandos a proposta de ensino, para que, cientes do que seria realizado, assinassem, se assim desejassem, o Termo de Consentimento Livre e Esclarecido. Foi também na ocasião que estes se apresentaram e comentaram sua relação prévia com o gênero textual em destaque. Na sequência, um diálogo sobre o título da HQ foi travado para que os estudantes externalizassem suas impressões frente a ele. Posteriormente, foi lido o trecho relativo às páginas $1-15$ e discutido o primeiro fragmento da obra.

Segundo Encontro: ocorreu a leitura de mais um fragmento da obra (páginas 16-29). Em seguida, duplas ou trios de alunos identificaram trechos que representassem características da atividade científica (construção da ciência), abordados na HQ até então, conforme Ferreira e Queiroz. ${ }^{11}$

Ainda neste encontro, como tarefa extraclasse, foram realizadas duas solicitações aos estudantes: a primeira que argumentassem por escrito sobre a necessidade, ou não, de investimento em armamentos
III: Discussão oral e conjunta acerca dos posicionamentos e argumentos iniciais
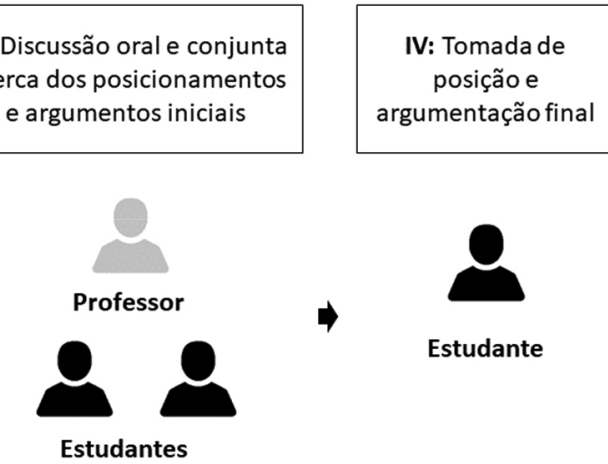

nucleares em território nacional, em uma carta hipoteticamente endereçada ao Presidente da República. A segunda, conforme ilustrado a seguir, exigia um levantamento do contexto social da época, tendo em vista a familiarização dos licenciandos com o ambiente no qual a HQ se desenvolvia:

Observa-se a partir da leitura inicial do livro "Trinity: a história em quadrinhos da primeira bomba atômica" que a informação apresentada se dá por meio de uma abordagem, a princípio, histórica. Dessa forma, para auxílio na compreensão da narrativa, bem como para entender a relação existente entre ciência e sociedade durante a Segunda Guerra Mundial, é interessante entender o contexto social da época. Nessa perspectiva, busque informações que indiquem como se apresentava, nas décadas de 1930/1940, um dos seguintes aspectos: as opções de lazer como cinema, teatro ou literatura; os meios de comunicação de massa; os modos de trabalho; o funcionamento das universidades. Feita a busca, indique como o aspecto escolhido para sua pesquisa foi influenciado pela guerra, ou como este influenciou de alguma forma o conflito.

Terceiro Encontro: após a leitura das páginas 30-37, ocorreu a aplicação do primeiro estudo de caso, mencionado anteriormente. O Caso I aborda a questão relativa ao sigilo do Projeto Manhattan frente ao compartilhamento de ideias entre cientistas, decisão que, na história quadrinizada, recaía sobre o personagem Oppenheimer. Diante dessa situação, os alunos, assumindo o papel do físico norteamericano, precisavam argumentar se os cientistas deveriam se comunicar livremente dentro das instalações que compreendiam o Projeto Manhattan ou, se dadas as circunstâncias, essa opção seria inviável. O caso é finalizado com a questão: "Deveria Oppenheimer seguir com o plano de deixar os cientistas livres para falar o que quisessem, mas só dentro do laboratório, ficando por conta dos cientistas policiar a si mesmos? Por quê?”. A dinâmica seguida 
durante a aula foi aquela relacionada à aplicação de todos os estudos de caso (Figura 3).

Quarto Encontro: foi realizada a leitura das páginas 37-57. Na sequência, foi proposta uma atividade escrita com o intuito de fazer com que os alunos retomassem conhecimentos químicos fundamentais para o entendimento da HQ. Na primeira parte da atividade, os alunos precisavam indicar e definir os conceitos químicos expostos, desde o início da narrativa até a página 57 , relacionados ao processo de construção da bomba atômica, apontando a importância de cada um para o funcionamento efetivo da arma, enquanto que na segunda parte, a resposta ao seguinte questionamento precisava ser apresentada.

A HQ inicia com uma colocação do narrador sobre algumas descobertas científicas importantes: "A bomba - o segredo do seu poder extraordinário - foi concebida muitos anos atrás, na Europa". Assim, é apresentada a descoberta da radioatividade por Marie e Pierre Curie em 1898. Conhecendo os aspectos envolvidos na construção da bomba atômica na década de 1940, de que maneira, o "achado" do casal Curie se relaciona com a construção da arma?

Ao final do quarto encontro, uma atividade extraclasse foi atribuída aos estudantes, composta de duas partes: uma delas consistia na elaboração de uma ficha técnica de vídeos ou filmes que abordassem questões tratadas na obra, enquanto a outra dizia respeito a uma pesquisa sobre a bomba atômica Trinity e as que foram lançadas em Hiroshima e Nagasaki, cujo enunciado encontra-se a seguir. A atividade extraclasse procurou incentivar os alunos a tomarem conhecimento de informações que foram suprimidas da HQ, como o mecanismo detalhado de funcionamento das bombas lançadas nas cidades japonesas, as quais diferem entre si.

Para a realização do Teste Trinity e o sucesso da arma desenvolvida, várias questões tiveram que ser respondidas. Contribuiu para isso o estudo de cientistas envolvidos no Projeto Manhattan. No entanto, como indica a frase final do trecho lido em aula, "até então, as respostas existiam apenas no papel". Busque informações sobre as bombas lançadas nas cidades japonesas (Hiroshima e Nagasaki) e verifique se estas eram do mesmo tipo. Feito isso, indique os seus princípios e mecanismos de funcionamento. Caso existam diferenças entre as bombas, descreva-as no que diz respeito aos aspectos composicionais (materiais utilizados), estruturais (forma e modelo da bomba) e funcionais (mecanismos de funcionamento).

Quinto Encontro: foi realizado um primeiro feedback dos argumentos escritos, elaborados no terceiro encontro, para o Caso I. O docente fez uma apresentação, utilizando recursos audiovisuais, que incluiu a retomada do Modelo de Toulmin ${ }^{20} \mathrm{e}$, a partir dos seus elementos constitutivos, comentou os argumentos produzidos por todos os licenciandos tanto antes, como após a discussão realizada sobre o caso em questão. Dessa forma, os licenciandos observaram as abordagens e os elementos empregados pelos colegas em seus argumentos. Durante a apresentação, em alguns momentos, o docente solicitava aos autores dos argumentos que explicassem o que buscavam com determinadas afirmações, almejando torná-las mais claras. Na sequência, foi realizada a leitura das páginas 58-93 da HQ.

Sexto Encontro: Após a leitura das páginas 58-93, ocorreu a aplicação do segundo estudo de caso. Elaborado a partir de excertos extraídos das páginas 60-61 da HQ, o Caso II, A questão da comunicação científica, apresenta um dilema que se origina de diálogos ocorridos entre Bohr e Oppenheimer a respeito do sigilo do Projeto Manhattan. O primeiro cientista afirmava que o extremo cuidado com relação ao sigilo interno do Projeto não seria necessário se fosse falado abertamente a todos sobre o poder de destruição de um armamento como o que estava sendo desenvolvido. Sendo assim, acreditava Bohr, conhecendo tal poder, ninguém seria tolo em construir uma arma que poderia facilmente destruir o mundo. Mediante essas considerações do físico dinamarquês, os licenciandos eram solicitados a responder a seguinte questão que finaliza o caso: "Enquanto cientista responsável pelo Projeto Manhattan, deveria Oppenheimer falar abertamente sobre o poder de destruição da bomba atômica em construção? Por quê?". Novamente, a dinâmica seguida durante a aula foi aquela relacionada à aplicação de todos os estudos de caso (Figura 3). Ao final do encontro, foi solicitado que a leitura das páginas 94-129 acontecesse extraclasse.

Sétimo Encontro: foi realizada a leitura das páginas 130-151, que subsidiou a aplicação do terceiro e último estudo de caso, assim como a finalização do conteúdo da obra. O Caso III, As implicações do desenvolvimento científico, extraído das páginas 131-133 e 136 da obra, abordou implicações do desenvolvimento científico oriundo da bomba atômica, envolvendo questões políticas, científicas e sociais. Nesse contexto, a tomada de decisão proposta se deu em relação à construção, ou não, do aparato bélico, de modo que os licenciandos eram solicitados a responder a seguinte questão que finaliza o caso: "Enquanto cientista, você acredita que uma bomba atômica deveria ter sido feita? Por quê?". A dinâmica apresentada na Figura 3 foi outra vez adotada.

Oitavo Encontro: foi realizado um segundo feedback sobre os argumentos produzidos, dessa vez oferecido pelos próprios estudantes, resultante de um PPR (Figura 4).

O PPR se iniciou com a divisão dos estudantes, no papel de pareceristas, em duas duplas e um trio (I). Na sequência, o docente, que já havia transcrito todos os argumentos construídos em resposta à questão que finaliza o Caso II e os organizado como textos enumerados de 1 a 7 , a fim de manter a revisão por pares às cegas, realizou a distribuição dos mesmos entre os estudantes (II). Após a distribuição, os estudantes elaboraram os respectivos feedbacks e os discutiram internamente (III). Por fim, cada grupo selecionou um parecer em específico e o apresentou oralmente para colegas e docente (IV). Em sua maioria, os licenciandos conseguiram emitir o parecer a partir da discussão dos argumentos na perspectiva do Modelo de Toulmin. ${ }^{20}$

Conforme mencionado anteriormente, ao final do PPR, os participantes responderam a um questionário em escala Likert sobre as suas percepções a respeito das atividades desenvolvidas com base na HQ, cuja análise das respostas é discutida na sequência.

\section{PERCEPÇÕES DOS LICENCIANDOS SOBRE AS ATIVIDADES PAUTADAS NA HQ}

As dez afirmações existentes no questionário sobre as percepções dos licenciandos frente às atividades pautadas no uso de HQ são discutidas de forma fragmentada. As cinco afirmações iniciais, apresentadas a seguir, referem-se à compreensão de conteúdos de química e de características da atividade científica:

1. A leitura da HQ me ajudou a entender melhor os conceitos químicos envolvendo a estrutura do átomo.

2. A leitura da HQ me ajudou a entender melhor os conceitos químicos relacionados com o processo de construção de uma arma atômica (fissão nuclear, reação em cadeia, etc.).

3. A leitura da HQ me ajudou a relacionar os conceitos químicos abordados com o cotidiano.

4. A leitura da HQ me ajudou a compreender conteúdos não tradicionalmente incluídos no ensino formal de química, mas a ela relacionados. 


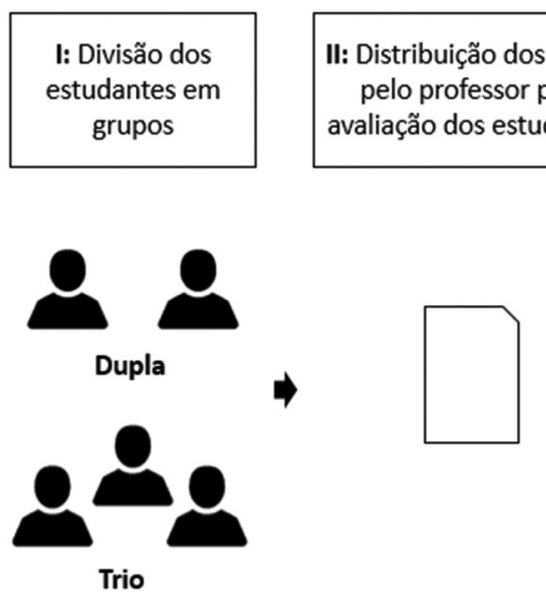

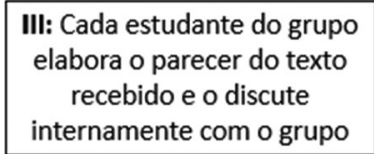

III: Cada estudante do grupo abora o parecer do tex internamente com o grupo

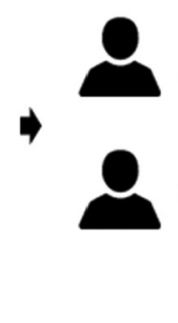

Estudante A

Parecerista do texto 1

Estudante B Parecerista do texto 2
IV: Estudantes apresentam oralmente um único parecer escolhido pelo grupo

Figura 4. Esquematização do PPR a respeito da resolução dos estudos de caso

5. A leitura da HQ me ajudou a entender melhor as características da atividade científica.

As três afirmações seguintes estão vinculadas à linguagem empregada na HQ:

6. A linguagem narrativa ilustrada (combinação de texto e imagem) facilitou a leitura da HQ.

7. O vocabulário (conjunto de palavras) empregado na HQ foi de fácil compreensão.

8. Em nenhum momento fiquei confuso(a) sem saber para qual quadro ou balão seguir na leitura da HQ.

As duas afirmações restantes relacionam-se às contribuições da HQ para a formação docente e para o processo de ensino-aprendizagem:

9. As habilidades que adquiri com as atividades envolvendo a leitura da HQ contribuíram para a minha formação profissional.

10. A integração de diferentes textos em sala de aula, como a HQ, contribui para a melhoria do processo de ensino e aprendizagem na educação básica.

A Figura 5 apresenta a quantificação da frequência das respostas, em porcentagem. $\mathrm{O}$ eixo x corresponde à frequência de respostas e o eixo y diz respeito à numeração das afirmações.

\section{Percepções quanto à compreensão de conteúdos de química e de caracterísiticas da atividade científica}

A Figura 5 mostra que a maioria dos estudantes concorda com as afirmações 1 a 5 , com destaque para a 2 e 5 , ambas com somatório das respostas concordo e concordo fortemente igual a $100 \%$. A afirmação 2 enfatiza as contribuições da leitura da HQ para a compreensão de conceitos químicos relacionados com o processo de construção de uma arma atômica, enquanto a afirmação 5 destaca as contribuições da leitura para o entendimeto de características da atividade científica. A elevada concordância frente à questão 5 está em sintonia com o que havia sido apontado no tópico de análise da HQ, quando foi identificada a presença marcante de diferentes características da atividade científica no texto quadrinizado. ${ }^{11}$ Logo, não é surpreendente que a leitura da HQ tenha permitido, de acordo com as respostas fornecidas pelos licenciandos, um entendimento mais amplo a seu respeito. Iniciativas voltadas ao uso de diversos artifícios para contemplar uma melhor compreensão dos educandos de todos os níveis de ensino sobre a natureza da ciência são recorrentes na literatura, ${ }^{21}$ sendo esse resultado animador, pois coloca a HQ no rol de possível recurso para tal alcance quando aplicada, por exemplo, da forma aqui descrita.

As afirmações 1, 3 e 4, assim como a 2, abordam a compreensão de conceitos químicos, seja daqueles que envolvem a estrutura do átomo e a construção de uma bomba atômica, seja dos que são vinculados ao cotidiano dos estudantes ou dos conteúdos que não são tradicionalmente incluídos no ensino formal. A expressiva concordância dos futuros professores às afirmações 2,3 e 4 (todas elas com mais de $86 \%$ no somatório das respostas concordo fortemente e concordo) também está em sintonia com o que havia sido apontado no tópico de análise da HQ, quando foi identificada, para além

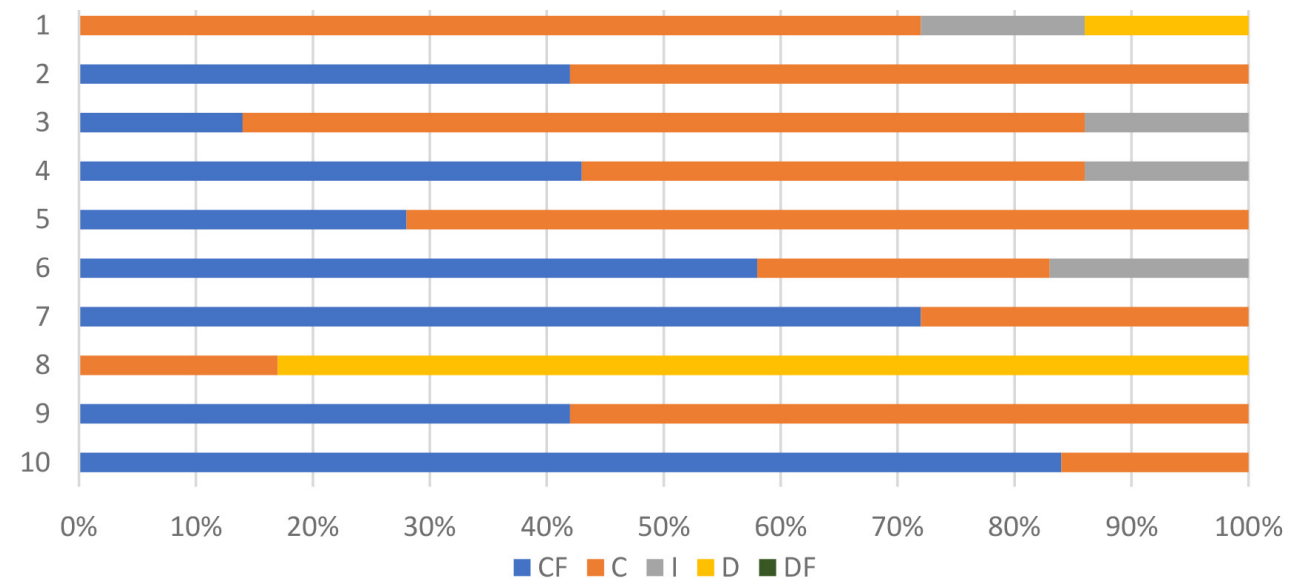

Figura 5. Questionário de percepção sobre as atividades pautadas no uso da $H Q$, no qual $C F=$ Concordo Fortemente, $C=C o n c o r d o, ~ I=I n d e c i s o, D=$ Discordo e DF = Discordo Fortemente 
da temática transversal ética, a presença de diferentes conteúdos classificados na categoria fronteiras, como a física e tópicos de radioatividade. Outrossim, a abordagem dos conteúdos veiculados no texto também permite ao leitor, na concepção dos futuros professores, o estabelecimento de relações entre o conhecimento científico e o cotidiano, o que segundo Cachapuz, Praia e Jorge, ${ }^{22}$ ao repensarem a epistemologia da educação científica, consiste em uma das orientações para o ensino de ciências.

Em contraponto, dentre as quatro afirmações iniciais, a 1 obteve um menor grau de concordância $(72 \%$, somatório das respostas concordo e concordo fortemente) e também um indicativo de discordância (14\%). Provavelmente, a abordagem sobre a estrutura do átomo oferecida na HQ, sem detalhamento dos diferentes modelos atômicos existentes e por meio de uma série de recursos metalinguísticos como simplificações e analogias, conduziram a esse resultado, que foi o menos positivo frente aos demais. Assim sendo, essa abordagem, associada aos pré-conceitos envolvendo a leitura quadrinizada,,${ }^{9,23}$ pode ter inibido os licenciandos a concordarem fortemente com a afirmação 1 .

\section{Percepções frente à linguagem da HQ}

As afirmações 6 a 8 dizem respeito às percepções dos licenciandos frente à linguagem da HQ. Considerando a afirmação 7, a qual trata do vocabulário nela empregado, observa-se, conforme ilustra a Figura 5, $100 \%$ de concordância (somatório das respostas concordo e concordo fortemente). Esse resultado vai ao encontro das características próprias desse hipergênero textual, tal como pontuado por Testoni, ${ }^{8}$ ao reforçar a simplicidade da linguagem escrita.

Considerando tais características desse hipergênero, as quais foram influenciadas pela sua própria constituição, é de se esperar uma linguagem mais acessível e o amplo uso de recursos visuais e textuais que contribuam para a compreensão das informações. Ademais, a expressiva concordância dos licenciandos com essa afirmação vai também ao encontro da análise da HQ apresentada previamente, quando foi identificada, para além de uma série de recursos metalinguísticos, a busca por um equilíbrio entre termos técnicos próprios da comunidade científica e termos comuns ao repertório do leitor não familiarizado com ela.

A respeito da afirmação 6 , elevado grau de concordância também foi identificado (83\%, somatório das respostas concordo e concordo fortemente). Contudo, quando se considera, por exemplo, as potencialidades das HQ no ensino de ciências na perspectiva de Testoni ${ }^{8}$ e até mesmo a linguagem autônoma dos quadrinhos, essas respostas parecem divergir da literatura. Ou seja, uma vez que os quadrinhos possuem uma linguagem própria, marcada por regras e convenções, ${ }^{6}$ e nessa linguagem há o emprego de dois diferentes signos que implicam no exercício de uma série de atividades mentais para a adequada compreensão do texto, o cognitivismo promovido pelas HQ, na perspectiva de Testoni ${ }^{8}$ era de se esperar que a linguagem narrativa ilustrada dificultasse o processo de atribuição de sentidos. No entanto, o que se verificou nas respostas dos licenciandos foi o oposto, o que, por sua vez, pode ser atribuído a alguns motivos.

Primeiro, pode ter predominado, na percepção dos futuros professores a essa afirmação, a ideia de que ao ilustrar um texto, o autor emprega um tipo de recurso que facilita a sua interpretação. Outro motivo que pode ter conduzido a um grau elevado de concordância diz respeito à própria dinâmica de leitura estabelecida em sala de aula. Considerando apenas a linguagem verbal na maioria das vezes, uma vez que esta era lida em voz alta com a interpretação de papéis, a dificuldade inerente à linguagem dos quadrinhos não foi preponderante.

No que concerne à afirmação 8, em que se identificou o maior número de discordantes (83\%), as respostas dos licenciandos podem ter sido influenciadas por dois elementos da HQ. O primeiro diz respeito ao enquadramento pouco convencional do texto, sem a divisão clássica em quadros. E o outro se relaciona com as transições de cena próprias de uma arte denominada sequencial. ${ }^{7}$ Dessa forma, saltos temporais e espaciais maiores exigidos pela abordagem histórica adotada pelo autor unidos a enquadramentos não convencionais, podem ter colaborado para que os licenciandos ficassem confusos em diferentes momentos da leitura. Aqui salientamos o que Testoni ${ }^{8}$ denomina como cognitivismo inerente do processo de leitura de HQ. Para o autor, embora a linguagem escrita possa parecer simples a princípio, a combinação dos diferentes códigos gráficos exige um nível de atenção maior para o acompanhamento do fluxo narrativo e para conciliar esses códigos gráficos distintos (imagem e escrita).

Os resultados obtidos com as respostas oferecidas às afirmações deste bloco denotam, conforme evidenciado por Vergueiro e Ramos ${ }^{23}$ e Leite, ${ }^{9}$ a necessidade de inserção de mais práticas que permitam a familiarização dos futuros professores com a linguagem autônoma dos quadrinhos, ${ }^{6}$ de modo que sejam motivados a fazer uso dessa linguagem em sua prática pedagógica.

\section{Percepções frente às contribuições da HQ para a formação dos professores e para o processo de ensino e aprendizagem}

As afirmações 9 e 10 dizem respeito às contribuições da leitura da HQ para a formação dos licenciandos bem como para o processo de ensino e aprendizagem. Com base no que é exposto na Figura 5, verifica-se, mediante o elevado grau de concordância a ambas as afirmações (100\%, somatório de respostas concordo e concordo fortemente), que os futuros professores consideram as atividades empregadas em sala de aula de grande relevância também para aplicação na educação básica. Isso exposto, os resultados assumem grande valor quando se parte do pressuposto que as ações dos professores em sala de aula estão diretamente relacionadas com suas habilidades, bem como com os significados que estes atribuem às diferentes atividades. Nessa perspectiva, uma vez que os docentes não consideram determinada atividade relevante para a formação dos seus educandos, a probabilidade de desenvolvê-la de forma satisfatória em sala de aula é mínima. Nesse contexto, os resultados obtidos com as afirmações 9 e 10 reforçam o que vem sendo pontuado na literatura a respeito das potencialidades do uso de HQ em espaços formativos, com destaque para o ensino de ciências, e reiteram o que afirma Leite ${ }^{9}$ a respeito do uso desse hipergênero textual em sala de aula:

O potencial didático-pedagógico das histórias em quadrinhos envolve diversas aplicações como: incentivo à leitura, discussão de conteúdos científicos, uso de dramatização e divulgação científica. As HQs além de promoverem a prática da leitura, por aqueles estudantes que não são motivados a ler outro gênero, elas possibilitam uma aprendizagem diferenciada e marcante para o estudante (p. 61). ${ }^{9}$

\section{CONSIDERAÇÕES FINAIS}

A proposta de ensino aqui relatada indica a pertinência e viabilidade da inserção de obras quadrinizadas no ensino superior de química. Cabe também destacar o emprego desse hipergênero textual nos cursos de licenciatura, tendo em vista a necessidade de ampliar a visão dos futuros professores frente à sua aplicação em salas de aula.

No que diz respeito à $\mathrm{HQ}$ empregada, destaca-se de antemão que obras cujo objetivo primário não seja o educativo, também permitem, quando bem integradas na prática pedagógica, fomentar discussões científicas em diferentes níveis de ensino. Para isso é pertinente 
ressaltar a importância de uma pré-análise bem estruturada do texto de modo a identificar o seu potencial didático. Nesse contexto, a investigação acerca do conteúdo e da forma da HQ permitiu inferir sobre o seu potencial para o desenvolvimento de ações pautadas nos mais variados conteúdos de natureza científica, no tema transversal ética e no exercício da argumentação.

Partindo para as considerações a respeito da relação dos licenciandos em química com obras quadrinizadas e suas percepções quanto à integração desse hipergênero textual na educação científica, é evidente o distanciamento que ocorre, reforçado pelo próprio percurso formativo desses profissionais, entre os futuros professores e a leitura de tais obras. Esse distanciamento implica em um desconhecimento e certa estranheza a respeito da linguagem característica de textos dessa natureza, que apesar de concebida popularmente como simples, goza de elementos enriquecedores para fins educativos.

Ademais, observa-se com base nas percepções dos futuros professores, diferentes potencialidades vislumbradas para o emprego de HQ na educação científica, como para a promoção da argumentação ${ }^{24}$ e de questionamentos científicos e sociais, ${ }^{11}$ além de uma possível aproximação dos educandos com a prática científica. ${ }^{13}$ Assim sendo, quando é assumido que práticas pedagógicas bemsucedidas na educação básica estão diretamente relacionadas às habilidades e ao valor que os professores atribuem a determinadas atividades, caminhar para uma mudança de visão desses profissionais é um ponto de partida significativo.

Por fim, salienta-se que a análise da argumentação dos alunos frente ao Caso I pode ser encontrada em artigo intitulado História em quadrinhos como fio condutor na promoção da argumentação de licenciandos em química, publicado em número especial da revista Química Nova na Escola, dedicado à questão da argumentação no ensino de química no Brasil. ${ }^{25}$

\section{AGRADECIMENTOS}

O presente trabalho foi realizado com apoio da Coordenação de Aperfeiçoamento de Pessoal de Nível Superior - Brasil (CAPES) Código de Financiamento 001.

\section{MATERIAL SUPLEMENTAR}

O Material Suplementar está disponível em http://quimicanova. sbq.org.br com acesso livre e inclui a íntegra do primeiro estudo de caso aplicado em sala de aula a partir da leitura da HQ Trinity - $a$ história em quadrinhos da bomba atômica.

\section{REFERENCIAS}

1. Santos, L. C.; Silva, M. G. L.; Enseñanza de las ciencias: revista de investigacion y experiências didacticas, 2013, extra.

2. Cachapuz, A.; Gil-Perez, D.; Pessoa de Carvalho, A. M.; Praia, J.; Vilches, A.; A necessária renovação do ensino de ciências, Cortez: São Paulo, 2005.

3. Rodrigues, A. A. D.; Quadros, A. L.; Quim. Nova na Esc. 2018, 40, 126.

4. Camargo, S. C.; Rivelini-Silva, A. C.; ACTIO Docência em Ciências 2017, 3, 2.

5. Silva, G. B.; Queiroz, S. L.; Anais do XV Evento de Educação em Química, Araraquara, Brasil, 2017.

6. Ramos, P.; A leitura dos quadrinhos, $3^{\text {a }}$ ed. Contexto: São Paulo, 2016.

7. Eisner, W.; Quadrinhos e arte sequencial, $3^{\mathrm{a}}$ ed., Martins Fontes: São Paulo, 1999.

8. Testoni, L. A.; Dissertação de Mestrado, Universidade de São Paulo, Brasil, 2004.

9. Leite, B. S.; Revista Eletrônica Ludus Scientiae 2017, 1, 1.

10. Fetter-Vorm, J.; Trinity: a história em quadrinhos da primeira bomba atômica, Três Estrelas: São Paulo, 2013.

11. Ferreira, L. N. A.; Queiroz, S. L.; Quim. Nova 2011, 34, 2.

12. Salém, S.; Kawamura, M. R.; Atas do II Encontro Nacional de Pesquisa em Educação em Ciências, Valinhos, Brasil, 1999.

13. Sotério, C.; Queiroz, S. L.; Quim. Nova 2020, 43, 3.

14. http://basenacionalcomum.mec.gov.br/images/BNCC_EI_EF_110518_ versaofinal_site.pdf, acessada em fevereiro 2021.

15. McCloud, S.; Desvendando os quadrinhos: história, criação, desenho, animação, roteiro, M. Books: São Paulo, 2005.

16. Kress, G.; Literacy in the new media age, Routledge: São Paulo, 2003.

17. Zamboni, L. M. S.; Cientistas, jornalistas e a divulgação científica: subjetividade e heterogeneidade do discurso da divulgação científica, Autores Associados: Campinas 2001.

18. Francisco Junior, W. E.; Francisco, W.; Oliveira. A. C. G.; Ensaio 2012, $14,131$.

19. Kortland, K.; Sci. Educ. 1996, 80, 6.

20. Toulmin, S.; Os usos do argumento, Martins Fontes: São Paulo, 2001

21. Bejarano, N. N. R.; Aduriz-Bravo, A.; Bonfim, C. S.; Ciência \& Educação 2019, 25, 967.

22. Cachapuz, A.; Praia, J.; Jorge, M.; Ciência \& Educação 2004, 10, 3.

23. Vergueiro, W.; Ramos, P.; Os quadrinhos (oficialmente) na escola: dos PCN ao PNBE; Vergueiro, W., Ramos, P., orgs.; Contexto: São Paulo. 2009.

24. Leitão, S.; Uni-pluriversidad 2012, 11, 23.

25. Silva, G. B.; Queiroz, S. L.; Quim. Nova na Esc. 2021, 43, 4. 